\title{
Networks of Giving and Receiving in an Organizational Context: Dependent Rational Animals and MacIntyrean Business Ethics
}

\author{
Caleb Bernacchio \\ IESE Business School
}

\begin{abstract}
Alasdair MacIntyre's After Virtue has made a significant impact within business ethics. This impact has centered upon applications of the virtuesgoods-practices-institutions schema (Moore \& Beadle, 2006). In this article, I develop an extension of the practices-institutions schema (Moore, 2017), drawing upon MacIntyre's later text, Dependent Rational Animals. Two key concepts drawn from this text are "networks of giving and receiving" and "the virtues of acknowledged dependence." Networks of giving and receiving are non-calculative relationships that enable participants to cope with vulnerability. These relationships are sustained by the virtues of acknowledged dependence, including just generosity, misericordia, and beneficence, virtues that direct participants to treat the needs of others as reasons for action. Drawing upon research in social network theory, I develop an example illustrating the application of these concepts within an organizational and interorganizational context. I then suggest a number of applications and research questions related to this extension of the practices-institutions schema.
\end{abstract}

KEY WORDS: virtue ethics, Alasdair MacIntyre, social network theory

omewhat surprisingly given its strong critique of both management and formal organizations, MacIntyre's After Virtue (2007) has had a considerable impact on the field of business ethics (Beadle, 2015; Ferrero \& Sison, 2014). This influence has largely centered on applications of the virtues-goods-practices-institutions schema (Moore \& Beadle, 2006). Taking inspiration from a key passage in After Virtue (2007: 194), wherein MacIntyre argues that practices and institutions form a "single causal order," researchers have sought to empirically examine the way in which commitments to the internal goods of practices are sustained by the exercise of the virtues and threatened by the inordinate pursuit of external goods characteristic of institutions (see, for example, Beadle, 2013; Moore \& Beadle, 2006; Moore \& Grandy, 2017; von Krogh, Haefliger, Spaeth, \& Wallin, 2012).

In this article, I develop an extension of the virtues-goods-practices-institutions schema (Moore \& Beadle, 2006) by drawing upon MacIntyre's account of the virtues in Dependent Rational Animals (1999a; henceforth DRA). In this later text, MacIntyre (1999a: ix) argues that his earlier claims in After Virtue (2007; first published in 1981; henceforth $A V$ ) need to be partially corrected, or more specifically, that by focusing upon human vulnerability it is possible to "notice some other important aspects of the part that the virtues play in human life." As a means of extending his 
earlier account, MacIntyre introduces two key concepts, namely, the notion of "a network of relationships of giving and receiving" (1999a: 99) and "the virtues of acknowledged dependence" (1999a: 119). These are the relationships and virtues that enable participants to cope with vulnerability in order to flourish.

The remainder of this article proceeds as follows: In section one, I introduce MacIntyre's (1999a) account of both networks of giving and receiving and the virtues of acknowledged dependence, arguing that networks are normally located in, but extend beyond, local forms of community, being present, as well, in an organizational and interorganizational context. Following this, in section two, I distinguish networks of giving and receiving from both practices and institutions, highlighting the way in which the framework derived from DRA emphasizes goods and virtues that have not been adequately theorized in previous research. Section three presents an example drawn from social network theory (Uzzi, 1997), which illustrates the presence of relationships of giving and receiving within the supply chain of the New York women's garment industry. This is followed by a brief discussion of the potential for applications of the concept of networks of giving and receiving to extend research employing the good-virtues-practices-institutions schema (Moore \& Beadle, 2006) by linking practice-bearing institutions (Coe \& Beadle, 2008) with the common good of the political community (see Sison \& Fontrodona, 2012, 2013).

\section{NETWORKS OF GIVING AND RECEIVING WITHIN COMMUNITIES AND ORGANIZATIONS}

MacIntyre (1999a: 98) introduces the concept of networks of giving and receiving by explaining that he aims to "characterize more fully both the kind of ordered social relationships which the exercise of the virtues requires and the importance of some particular virtues that do not always receive their due in conventional accounts of the virtues." These ordered relationships, which he terms networks of giving and receiving, are non-calculative (MacIntyre, 1999a: 120, 2000: 83); they extend throughout the entire span of life (1999a: 9), and, within them, need provides an overriding reason for action (1999a: 108). Networks of giving and receiving not only include relationships between family members, friends, and coworkers, but also extend to commercial relations and strangers (MacIntyre, 1999a: 116-117, 125, 145; 2010: 8). These relationships serve as the foundation of the local political community (MacIntyre, 1999a: 129) because they enable community members to cope with vulnerability in order to achieve the goods needed to flourish.

MacIntyre (1999a: 157; see also 129-130) speaks of the local community as "embodying" networks of giving and receiving, especially within participatory and deliberative political institutions. However, it is evident that relationships of giving and receiving extend beyond any given institutional expression or local communal context (Dunne, 2002; MacIntyre, 1999a: 122-123). ${ }^{1}$ By introducing the concept of networks of giving and receiving, MacIntyre (1999a: 129-153) extends his previous discussion of the local political community as a type of higher-order practice (MacIntyre, 1989, 1994, 1998, 2007: 227), thereby explaining the relational basis of communal deliberation. 
According to MacIntyre (1999a: 126), networks of giving and receiving are relationships between community members that engage the affections of participants and issue in uncalculating actions that lack strict proportionality in terms of giving and receiving. As these relationships are directed toward meeting the needs of community members, they extend beyond the strict calculations typical of market exchanges, which MacIntyre (1999a: 117) argues must always be "embedded in and sustained by relationships governed by norms of uncalculating and unpredicted giving and receiving." Such relationships of giving and receiving enable community members to cope with vulnerability in order to meet their needs, which are, at times, far-reaching and unforeseen (MacIntyre, 2010).

Relationships of giving and receiving are sustained by the virtues of acknowledged dependence, which MacIntyre (1999a: 129) describes as "the necessary counterpart to the virtues of independence." The account of the virtues of acknowledged dependence extends MacIntyre's $(1989,1997,2007)$ earlier analysis by emphasizing aspects of the virtues that were not adequately accounted for previously (1999a: ix), especially with regard to their role in sustaining the uncalculating relationships of giving and receiving that enable participants to cope with vulnerability. Among the virtues of acknowledged dependence, just generosity and misericordia stand out.

Just generosity goes beyond the strict requirements of legality, directing community members to act with liberality (MacIntyre, 1999a: 120) toward fellow community members, which concerns what Aquinas terms the "moral due" (ST II-II 117, 5). In this way, liberality, along with other virtues such as generosity, charity, and mercy, perfect the virtue of justice by better enabling it to achieve its end of a well-ordered community, as when acts of forgiveness serve to restore well-ordered relationships after civil war (Philpott, 2012: 271-273). Because of this, paradoxically, at times the requirements of justice go beyond a concern for strict proportionality. MacIntyre accounts for this need to go beyond the strict proportionality of justice with the notion of just generosity. As such, just generosity is not merely an optional virtue, but rather an obligation founded upon the vulnerability and mutual commitments of community members. Just generosity is typically expressed in reciprocal but uncalculating acts of care between persons who treat each other's needs as reasons for action (MacIntyre, 1999a: 122). When this occurs, just social relationships are sustained by generous acts of giving and receiving.

MacIntyre (1999a: 125) explains the notion of misericordia, a term that may be translated as "mercy" or "pity," by stating that it "is that aspect of charity whereby we supply what is needed by our neighbour." Unlike just generosity, which captures the reciprocal liberality necessary to sustain long-term relationships, misericordia is directed toward alleviating "urgent need," and, as a result, it may provide a more salient reason for action than even social or familial ties (MacIntyre, 1999a: 124). Indeed, it serves to "extend one's communal relationships," thereby ensuring that communal boundaries are porous, that is, open to encounters with non-members (MacIntyre, 1999a: 125).

As such, misericordia reflects a judgment concerning both the importance of care within one's relationships and encounters with others and one's own vulnerability and need for care in order to flourish (MacIntyre, 1999a: 107-109). By exercising the 
virtues of just generosity and misericordia, one promotes relationships constitutive of the common good, establishing the conditions needed to ensure one's own flourishing (MacIntyre, 1999a: 158-160). These virtues are complemented by gratitude, industriousness, and other virtues that may play a role in sustaining networks of giving and receiving (MacIntyre, 1999a: 126). Thus, the account of networks of giving and receiving contained in DRA extends MacIntyre's (2007) earlier account of practices, institutions, and communities by illustrating the indispensability of uncalculating relationships that are sustained by virtues that serve to direct agents toward the needs of others.

Although networks of giving and receiving are closely linked with local communities (Moore, 2008), they should not be viewed as narrowly tied to a specific geographic context, as MacIntyre (1999a: 122-123) himself cautions. Dunne (2002: 351) lends support to the adoption of a broad scope for the notion of networks of giving and receiving, arguing that $D R A$ provides a number of "qualifications about community... perhaps a concession, not granted in $A V$, to specifically modern conditions... that I may simultaneously belong to several communities and move consecutively in and out of different communities." He further claims that, for MacIntyre, such concessions effectively "explode the boundaries of community altogether" (Dunne, 2002: 351). Thus, although relationships of giving and receiving form the basis of local political communities, they are not limited to small-scale or geographically isolated communities. MacIntyre suggests that such relationships are widespread in contemporary society (MacIntyre, 2000, 2010; MacIntyre \& Voorhoeve, 2011) and, due to the ubiquity of vulnerability (MacIntyre, 1999a: 1-4), they should be present in various contexts, including organizational contexts (Lawrence \& Maitlis, 2012).

There are a number of additional reasons to support the claim that networks of giving and receiving are likely to be found in an organizational and interorganizational context. First, MacIntyre (1999a: 145) notes that "workplaces" may already be characterized by "groups whose social relationships are those of giving and receiving," since organizations are embedded within the context of particular communities. Likewise, it can be argued persuasively from an Aristotelian perspective (Hartman, 1996, 2013; Melé, 2012; Sinnicks, 2014: 245; Sison \& Fontrodona, 2012, 2013) that a firm is a type of moral community, which suggests that organizations are likely to embody relationships of giving and receiving. Drawing upon feminist ethics, researchers have made similar claims regarding the presence of relationships based on solidarity and care within and between organizations (Lawrence \& Maitlis, 2012; Wicks, Gilbert, \& Freeman, 1994). Finally, there exists significant empirical evidence regarding the widespread presence of prosocial behavior within organizations (see Beadle \& Knight, 2012: 443-446; Grant, 2007, 2008, 2014; Grant, Dutton, \& Rosso, 2008; Grant \& Gino, 2010; Grant \& Mayer, 2009). From a MacIntyrean perspective, organizations have been conceptualized as practice-institution combinations (MacIntyre, 2007; Moore, 2012b). In the following section, I distinguish the goods of networks of giving and receiving from those of practices and institutions, arguing that the framework drawn from DRA provides additional scope for the role of the virtues in an organizational and interorganizational context. 


\section{DISTINGUISHING NETWORKS FROM PRACTICES AND INSTITUTIONS}

Networks of giving and receiving extend practices and institutions because they are directed toward a more inclusive good. Where practices are centered upon internal goods and institutions upon external goods, networks of giving and receiving, by enabling participants to cope with vulnerability and meet their needs, are "constitutive means" toward the wellbeing, or flourishing, of participants (MacIntyre, 1999a: 102). Practices are also directed toward human flourishing, although they primarily contribute to human flourishing through their focus on the internal goods specific to the practice. MacIntyre (2016: 229, 1999a: 67) understands human flourishing to be a higher-order good that does not "compete with other goods," but, rather, is constituted by their proper ordering. Thus, participants in relationships of giving and receiving, who aim to meet the needs of others, enable fellow participants to flourish, and, by providing different forms of care, participants sustain the relationships that are required for their own flourishing (MacIntyre, 1999a: 158). ${ }^{2}$

A comparison with practices found among the medical professions is instructive. While nursing involves the care of patients (Armstrong, 2006, 2007), this is typically limited by the nurse's particular role such that certain forms of care are required and others are very clearly excluded. Nurses, for instance, are not typically required to assist their patients with financial matters. Similarly nurses, like participants in networks of giving and receiving more generally, direct their attention to the wellbeing of patients, but they do so by focusing upon the goods internal to the practice of nursing, goods typically related to the patient's physiological or psychological needs. In contrast, participants in networks of giving and receiving meet the needs of their fellow participants through a variety of means, that is, by assisting in achieving internal goods in various practices, by providing external goods, but also through more immediate forms of care (MacIntyre, 1999a, 2010). But it should be noted that the greater familiarity characteristic of relationships of giving and receiving - the concern for participants' "particularity" (MacIntyre, 1999a: 160)—may also result in a better ability to achieve the internal goods of a practice, for instance, when friendship develops between a nurse and her patient, such that the nurse better understands the patient's needs. In this way, the formation of relationships of giving and receiving between practitioners may both allow members of practices to cope with vulnerability associated with a range of goods and better enable them to achieve the internal goods of the practice.

More generally, the obligations between members of a practice (Hall, 2011; MacIntyre, 2007: 191; Sellman, 2000) differ from those typical of networks of giving and receiving (MacIntyre, 1999a, 2010: 8), but since the exercise of the virtues within practices will often lead to the formation of friendships and other relationships of giving and receiving, which are shaped by the virtues of just generosity, beneficence, and misericordia (MacIntyre, 1999a: 120-122), the distinction between practices, institutions, and networks of giving and receiving must be qualified. And as noted above, insofar as networks of giving and receiving extend practices, they may enable participants in practices to better achieve the internal goods of the practice. 
Relationships of giving and receiving may develop within the context of either practices or institutions, since relationships governed by the internal goods of practices or the external goods of institutions may advance into more robust relationships of giving and receiving that are founded upon mutual care. ${ }^{3}$ In this situation, the reasons for action founded upon the norms and incentives of institutions or the internal goods and standards of excellence of practices will be governed by a higher-order concern for the mutual wellbeing of participants and the preservation of the network of giving and receiving (see MacIntyre, 2016: 144-156). Due to this potential for overlap, the framework outlined in $D R A$, including networks of giving and receiving and the virtues of acknowledged dependence, is best understood as an extension of the virtues-goods-practices-institutions schema (Moore \& Beadle, 2006), which highlights those goods and virtues that were not adequately emphasized previously (MacIntyre, 1999a: ix). ${ }^{4}$

In DRA, MacIntyre (1999a: 66-68) identifies a fourfold classification of goods (see Table 1) that distinguishes the goods characteristic of practices, institutions, and networks. This account expands ${ }^{5}$ upon previous discussions involving a threefold categorization of goods (MacIntyre, 2007: 203, 2008: 267). The first and second categories concern internal and external goods, respectively. The third category concerns human flourishing, which is a higher-order good encompassing the proper ordering of goods in individual or communal life (for the Aristotelian roots of this notion of flourishing see MacIntyre, 1989: 107; see also Wolfe, 2016). This category concerns the goods of individuals and groups "not only qua agents engaged in this or that form of activity in this or that role or roles, but also qua human beings" (MacIntyre, 1999a: 67). MacIntyre (1999a: 68) also introduces an additional category of goods concerning pleasure derived from the satisfaction of urgent bodily wants.

Practices are primarily directed toward internal goods, while institutions are directed toward external goods (MacIntyre, 2007: 196), although there is an "essential but complex circularity between internal goods and external goods" (Moore, 2012b: 380) since these goods are involved in complex and often indirect causal relationships within the context of a specific practice-bearing institution. Thus, managers of practice-bearing institutions (Coe \& Beadle, 2008) must be concerned with

Table 1: Four Types of Goods

\begin{tabular}{|c|c|c|c|}
\hline Type of good & Description & Example & Primary social context \\
\hline $\begin{array}{l}\text { Flourishing/goods of } \\
\text { life as a whole }\end{array}$ & $\begin{array}{l}\text { Proper ordering of goods } \\
\text { of individual and } \\
\text { community life }\end{array}$ & $\begin{array}{l}\text { Common good of } \\
\text { community, flourishing } \\
\text { individual }\end{array}$ & $\begin{array}{l}\text { Networks, narratives, } \\
\text { political/governance } \\
\text { practices }\end{array}$ \\
\hline Internal goods & $\begin{array}{l}\text { (1) Excellent product and } \\
\text { performance } \\
\text { (2) Form of life }\end{array}$ & $\begin{array}{l}\text { (1) Excellent painting } \\
\text { (2) Life as painter }\end{array}$ & Practices \\
\hline External goods & Zero-sum and competitive & Money, power, status & Institutions \\
\hline $\begin{array}{l}\text { Pleasure from satisfaction } \\
\text { of bodily wants }\end{array}$ & $\begin{array}{l}\text { Felt wants related to } \\
\text { bodily functions }\end{array}$ & $\begin{array}{l}\text { Food, urgent medical } \\
\text { care, etc. }\end{array}$ & $\begin{array}{l}\text { Networks, institutions, } \\
\text { and practices }\end{array}$ \\
\hline
\end{tabular}


the goods internal to practices (see Beadle, 2013; Moore, 2012a) in order to preserve their institution. Similarly, goods concerning urgent bodily wants of various types also fall within the scope of any number of practices or institutions, for example, practices among the medical professions (Hall, 2011; Sellman, 2000, 2011) and institutions such as hospitals. Likewise, goods concerning urgent bodily wants fall within the scope of relationships of giving and receiving (MacIntyre, 1999a: 68, 2010: 8), although the range of goods with which networks are concerned extends beyond urgent bodily wants.

Networks of giving and receiving go beyond practices and institutions because they are relations that enable human beings to cope with vulnerability (MacIntyre, 1999a: 67). Human beings are vulnerable to anything that might interfere with their flourishing (MacIntyre, 1999a: 63). As flourishing is a higher-order good, it encompasses goods from each category, since goods of all types are required for flourishing (MacIntyre, 1999a: 68). As a result, relationships of giving and receiving that enable participants to cope with vulnerability must extend beyond a limited concern for internal goods, external goods, or urgent bodily needs in isolation to a concern for the wellbeing, or flourishing as such, of all participants, including the flourishing of both the giver and the receiver of care.

Participants within practices have distinct obligations to their fellow participants (Hall, 2011; MacIntyre, 2007: 194) based upon the internal goods of the particular practice. MacIntyre (2007: 192) emphasizes the role of justice, truthfulness, and courage in facilitating the achievement of goods internal to practices. Shared commitments to the standards partially constitutive of the practice facilitate inquiry, which enables participants to better achieve the goods internal to that practice (MacIntyre, 2007). Senior practitioners play an important role here by continuing to mentor and provide assistance to junior colleagues even after formal training periods end (Hall, 2011), although these efforts are primarily focused upon the achievement of goods internal to the practice. As such, practices provide the locus for an initial and partial specification of the requirements of the virtues (MacIntyre, 2007: 191).

The framework outlined in DRA extends the role of the virtues beyond a mere focus upon the internal goods of practices by highlighting the way in which relationships of giving and receiving centered upon the wellbeing of fellow participants are sustained by the virtues of acknowledged dependence (MacIntyre, 1999a: 119--28). Due to their focus on the threats to flourishing to which participants are vulnerable (MacIntyre, 1999a: 66-68), the obligations between participants in networks of giving and receiving extend beyond those typical of members of practices, at times requiring participants to forego their own goals in the face of the urgent needs of others (MacIntyre, 1999a: 126, 2010: 8). Thus, within networks of giving and receiving, obligations between participants are founded upon the mutual wellbeing, or flourishing, of participants, such that participants treat the needs of fellow participants as reasons for action (MacIntyre, 1999a: 122).

Members of practices also have obligations to beneficiaries of the practice and, more generally, to the common good of the wider community. Although this is especially evident in the case of the medical professions (Sellman, 2000), the obligation to contribute to the common good extends to all practices (MacIntyre, 2007; 
Moore, 2012a, 2012b). However, the contribution to the common good made as a participant in a practice differs from the contribution made as a member of a network of giving and receiving, as do the obligations demanded of participants (MacIntyre, 2010: 8). Practitioners primarily contribute to the common good through achieving those goods internal to the practice, especially excellent products and performances (MacIntyre, 2007, 2008; Moore, 2012a; Moore \& Grandy, 2017). Acknowledging that they belong to networks of giving and receiving, participants also contribute to the common good by enabling fellow participants to cope with threats to human flourishing (MacIntyre, 1999a: 66-68, 2000, 2010) and, more generally, by enabling fellow participants to develop their natural capabilities, especially those of practical rationality (MacIntyre, 1999a: 105).

By directing participants in networks of giving and receiving toward the needs of others (MacIntyre, 1999a: 157), virtues such as just generosity, beneficence, and misericordia require that one be willing "to be interrupted in one's projects," thereby manifesting "a willingness to turn aside from whatever good one is at that moment aiming to achieve or is in the course of achieving, so as to provide aid to those in urgent need" (MacIntyre, 2010: 8). Thus, the commitment due to fellow members within networks of giving and receiving is based upon the needs of participants, needs that extend beyond the internal goods of a particular practice. Just as the virtues require practitioners to direct the internal goods of practices to the common good of the wider community, the virtues of acknowledged dependence require a willingness on the part of participants in relationships of giving and receiving to place the needs of others above their own particular goals as a means of promoting the common good of the community (MacIntyre, 1999a: 113, 2010: 8). In doing so, participants establish the conditions necessary for their own flourishing (MacIntyre, 1999a: 158), social relationships wherein members are able to cope with vulnerability. In this way, networks of giving and receiving are "constitutive means," or integral components, of human flourishing and the common good (MacIntyre, 1999a: 102).

MacIntyre (1999a) explains the essential characteristic of networks of giving and receiving in terms of Aristotle's notion of friendship. He argues that the way in which "the virtues enable us to view ourselves and others ... as actual or potential members of some network of giving and receiving, is perhaps best captured by Aristotle's ... [notion of friendship], where he argues that, insofar as we are good, we stand to ourselves, just as we stand to our friends, and vice versa" (MacIntyre, 1999a: 160). According to Aristotle, friendship based upon virtue is directed toward the wellbeing of friends, since they "wish good to their friend for the friend's own sake" (Aristotle: NE 1156b 5-10; see also Melé, 2009). ${ }^{6}$

Friendship is a paradigmatic example of a relationship of giving and receiving, although such relationships extend beyond the bounds of friendship and include relationships between strangers (MacIntyre, 2010). What distinguishes networks of giving and receiving is the fact that participants are directed toward the mutual wellbeing of fellow participants by treating the good of others as their own good (MacIntyre, 1999a: 108). This is accomplished through the exercise of the virtues of acknowledged dependence, which direct agents to treat the needs of others as reasons for action (MacIntyre, 1999a: 157). 
This link with friendship also explains why networks of giving and receiving may partially overlap with both practices and institutions, although the rationale behind these respective social relationships differs. Relationships between members of a practice must be structured in terms of the virtues, especially the virtues of justice, truthfulness, and courage (MacIntyre, 2007: 192). These virtues ensure that practitioners treat fellow participants according to the standards partially constitutive of the practice, while their widespread absence makes it increasingly difficult to achieve the internal goods of the practice. However, insofar as participants are virtuous, a shared concern for the goods internal to the practice will often expand to include a mutual concern for the wellbeing of participants, and that concern will often expand into a type of friendship. In other words, the virtues-especially the virtue of justice - possess an intrinsic finality directed toward friendship (see Rhonheimer [2011:233] for the relationship between justice, benevolence, and friendship) and the common good of the political community (Beadle, 2008: 231; MacIntyre, 1994: 284).

Due to this intrinsic finality, practices will commonly become the site of virtuous friendships, a fact that has important implications for the way in which researchers understand the role of the virtues within practice-institution combinations (Moore, 2017). Again, a primary example is Aristotle's discussion of virtuous friendship between philosophers, wherein the shared concern for the goods of a philosophical life extends to include a mutual concern for the friend's wellbeing (see $N E$ Book 8). ${ }^{7}$ Even barring friendship, practitioners, especially when working in close proximity, will often develop a shared concern for their fellow practitioners' wellbeing, a concern that extends beyond that of internal goods (see Aristotle on goodwill and concord, NE 1166b 20-1167b: 10).

For similar reasons, networks of giving and receiving are likely to overlap with institutions. Due to the ubiquity of vulnerability (MacIntyre, 1999a) within an organizational context (Lawrence \& Maitlis, 2012), members of institutions will have good reason to form relationships of giving and receiving in order to cope with the threats to flourishing that arise from competitive relationships (MacIntyre, 1999a: 117, 2007: 194). Yet, institutions cannot be identified with networks of giving and receiving, since the former are characterized by competitive relationships focused on the attainment of zero-sum goods (MacIntyre, 2007: 190), whereas the latter are characterized by cooperative relationships (MacIntyre, 1999a: 120, 2007: 194) directed toward the common good of participants. ${ }^{8}$ Within institutions, external goods are typically distributed in terms of contractually defined relationships (Jensen \& Meckling, 1976), but relationships of giving and receiving are uncalculating (MacIntyre, 1999a: 126). Due to this, networks of giving and receiving cannot be identified with institutions.

The reason for action typical of participants is primarily what distinguishes practices, institutions, and networks of giving and receiving (MacIntyre, 1999a: 108; 2007: 194). Within practices, participants are primarily motivated by internal goods, within institutions by external goods, and as members of a network of giving and receiving, the mutual wellbeing of participants. This explains in part why MacIntyre (1999a: 8) distinguishes two sets of virtues characteristic of practices and networks, respectively, the virtues of independent rational agency and the virtues of 
acknowledged dependence and, similarly, the reason why he cautions against the vices commonly found within institutions (MacIntyre, 2007: 195; see also Setiya, 2007 on the connection between reasons for actions and states of character). In the example that follows, I highlight a context wherein the virtues of acknowledged dependence are especially salient, although, as MacIntyre (1999a: x) argues, the framework elaborated in $D R A$ extends the virtues-goods-practices-institutions schema (Moore \& Beadle, 2006), thereby highlighting a further role for the virtues within human life. Accordingly, the distinction between practices, institutions, and networks of giving and receiving (see Table 2) is something of an abstraction, since the same persons may frequently take part in each of these social relationships within the same organization. However, following the approach of MacIntyre (1999a: 108), I argue that networks of giving and receiving are distinct insofar as participants treat the needs and wellbeing of their fellow participants as reasons for action, beyond their concerns for the internal or external goods of a specific activity. The following section illustrates the presence of relationships of giving and receiving within an organizational context, and it highlights the way in which a shared concern for the wellbeing and vulnerability of participants drives virtuous behavior.

\section{NETWORKS OF GIVING AND RECEIVING IN THE APPAREL INDUSTRY}

In this section, I develop an example from Uzzi's (1997) study of networks of suppliers in the New York City apparel industry because it illustrates the main themes of DRA discussed in sections one and two above. Uzzi (1997) conducted interviews with CEOs and selected employees, as well as field and ethnographic research, at twenty-three women's better-dress firms in New York. One major finding of his study was a high degree of cooperation between members of different firms within the supply chain (Uzzi, 1997: 61). While this may be unsurprising from a broadly Aristotelian perspective (Hartman, 2013; Sison \& Fontrodona, 2012, 2013), a number of leading theories of organization have denied that genuine cooperation has a place within the firm, treating relationships between employees as merely contractual (Jensen \& Meckling, 1976; Fontrodona \& Sison, 2006) and asserting that trust within a commercial context is always calculative (Williamson, 1993). Likewise, MacIntyre (1979) has argued that membership in a modern corporation-at least insofar as practices are marginalized-is incompatible with genuine moral judgment.

Table 2: Comparing Networks, Practices, and Institutions

\begin{tabular}{|c|c|c|c|}
\hline Social context & Description & Example & Characteristic good \\
\hline $\begin{array}{l}\text { Networks of giving } \\
\text { and receiving }\end{array}$ & $\begin{array}{l}\text { Order of individual } \\
\text { or community life }\end{array}$ & $\begin{array}{l}\text { Common good of community, } \\
\text { flourishing individual }\end{array}$ & $\begin{array}{l}\text { Flourishing or wellbeing } \\
\text { of participants insofar as } \\
\text { this is threatened }\end{array}$ \\
\hline Practices & Craft-like activity & Medicine & Internal goods of practice \\
\hline Institutions & Formal organization & Hospitals & $\begin{array}{l}\text { External goods (i.e., money, } \\
\text { power, or status) }\end{array}$ \\
\hline
\end{tabular}


This example suggests that relationships of giving and receiving between organization members facilitate moral agency in a manner that is not sufficiently acknowledged by the leading theories of management and business ethics.

\section{Cooperation Across Activities and Mutual Concern for Wellbeing}

Several factors render this example especially apt. First, it provides a context where cooperation between participants in a range of activities-some clearly practices or practice-like activities (see Moore \& Grandy [2017: 12] on the notion of a sub-practice), others more properly viewed as skills (MacIntyre, 2007: 193; Moore, 2017: 142)— occurs across such activities (Beadle, 2015: 4). In this context, production begins with the manufacturer, or "jobber," who designs sample garments, frequently with assistance from a design consultant, and markets them to retailers. Once a buyer is found, the manufacturer contracts with a number of firms that actually manufacture the product, including grading, cutting, and sewing firms, as well as textile mills. As I argue in greater depth below, this provides an example of a form of cooperation that extends beyond a shared concern for internal goods, illustrating the way that networks of giving and receiving extend the virtues-goods-practices-institutions schema (Moore \& Beadle, 2006).

Similarly, as the example (Uzzi, 1997) makes evident, cooperation in this context has much more to do with coping with vulnerability related to unforeseen contingencies than achieving the specific excellence characteristic of the production process, illustrating the way in which reasons for actions within networks of giving and receiving extend beyond the internal goods of practices, providing a further rationale for the practice of the virtues within and between organizations. Often, the basis of cooperation is expressed in terms of participants' mutual concern for the wellbeing of other members of their network. In an illustrative quote, one CEO explained, "It is hard to see for an outsider that you become friends with these people-business friends. You trust them and their work. You have an interest in what they're doing outside of business" (Uzzi, 1997: 43). In this context, threats to the internal goods of the relevant practices were understood in terms of their negative impact upon the flourishing of fellow participants, such that a concern for meaningful work (Beadle \& Knight, 2012; Moore, 2017: 142) was contextualized in terms of a mutual concern for participants' flourishing.

Thus, this example illustrates the way in which mutual concern for the wellbeing of fellow participants is a key driver of cooperation in a manner that extends beyond a mere concern for excellence in production. The example also demonstrates the way in which the requirements of the virtues characteristic of participation in relationships of giving and receiving differ from the requirements typical of practices. As noted previously, relationships between practitioners are defined in terms of the virtues (MacIntyre, 2007: 191). Justice demands that participants treat each other according to the standards partially constitutive of the practice. Similarly, truthfulness and courage require participants to subordinate external goods to the internal goods of the practice, either by reporting performance in light of the standards of the practice, or by resisting institutional pressures regarding the prioritization of external goods. Within practices, the virtues often require participants, especially 
senior practitioners (MacIntyre, 1999a Hall, 2011), to offer care and assistance to other participants in order to enable novices to better succeed in the practice, although this care is focused on achieving the internal goods of practice and does not ordinarily extend to a general concern for fellow practitioners' wellbeing. For example, Hall (2011) recounts how senior surgeons provide continuing assistance to more junior practitioners when they are faced with difficult surgical procedures.

However, within networks of giving and receiving, the virtues of acknowledged dependence direct participants to treat the needs of others as reasons for action (MacIntyre, 1999a: 108). This concern surpasses the requirements typical of participation in a practice and it extends to a mutual concern for wellbeing, thereby enabling participants to cope with threats to any of the goods necessary for flourishing. This mutual concern for wellbeing is readily apparent in the present example.

\section{Wellbeing, Cooperation, and Vulnerability}

One important finding of this study is that interactions between members of firms within the supply chain "can be accurately summarized by two forms of exchange: arm's-length ties, referred to by interviewees as 'market relationships,' and embedded ties, which they called "close or special relationships"' (Uzzi, 1997: 42). The market relationships were arm's-length relationships, but what was especially striking was the "detached language" that the interviewees used to describe such relationships. Indeed, one interviewee referred to market relationships as "one-shot deals," where "you discuss only money" (Uzzi, 1997: 41), while another said, "They're relationships that are like far away. They don't consider the feeling for the human being" (Uzzi, 1997: 41).

This contrasts with embedded ties, which are "distinguished by the personal nature of the business relationship" (Uzzi, 1997: 41-42). As noted above, one CEO used the language of friendship to describe his attitude toward embedded ties. The participants distinguished between the robust concern manifested between embedded ties and the detached and calculative attitude typical of relationships among arm's-length ties. Between embedded ties there was something like a friendship, "a feeling for the human being," that extended beyond typical economic conceptions of relationships within a commercial context (Williamson, 1993). This is especially important because MacIntyre (1999a: 160) has argued that Aristotelian friendship offers a paradigmatic example of a relationship of giving and receiving, as noted above. Uzzi (1997: 56) argues, "one explanation is that, with the blending of the social and economic lives of actors, relationships take on an existence of their own that remains after the economic transaction ends," which suggests that these relationships manifest genuine friendships (see also Mele, 2009).

Embedded ties' mutual concern was manifested in joint problem solving and improved communication, which enabled the participants to cope with vulnerability related to unforeseen contingencies. For example, Uzzi (1997: 47) notes:

A contractor showed me a dress that he had to cut to different sizes depending on the dye color used because the dye color affected the fabric's stretching. The manufacturer who 
put in the order didn't know that the dress sizes had to be cut differently to compensate for the dyeing. If the contractor had not taken the initiative to research the fabric's qualities, he would have cut all the dresses the same way-a costly mistake for the manufacturer and one for which the contractor could not be held responsible. Both the manufacturer and the contractor reported that this type of integration existed only in their embedded ties, because their work routines facilitated troubleshooting and their "business friendship" motivated expectations of doing more than the letter of a "contract."

It is especially significant that the mutual commitment characteristic of embedded ties resulted in efforts to protect partners from unforeseen contingencies, thereby enabling them to cope with vulnerability. Speaking of the same incident, the manufacturer noted, "When you deal with a guy you don't have a close relationship with, it can be a big problem. Things go wrong and there's no telling what will happen. With my guys [his key contractors], if something goes wrong, I know we'll be able to work it out" (Uzzi, 1997: 47).

Considering the hypothetical situation of an unexpected problem with an order, another interviewee stated:

With people you trust, you know that if they have a problem with a fabric they're just not going to say, "I won't pay" or "take it back." If they did then we would have to pay for the loss. This way maybe the manufacturer will say, "OK so I'll make a dress out of it or I can cut it and make a short jacket instead of a long jacket" (Uzzi, 1997: 43).

In this case, the contractor expressed trust that the manufacturer would adapt production plans to ensure that the contractor was not faced with a loss as a result of an unforeseen problem. Among embedded ties there exists a mutual willingness to take extra (noncontractual) precautions to ensure the wellbeing of close partners and, likewise, to preserve the relationship itself. Along these lines, another interviewee highlighted the importance of mutual concern, stating:

I'd rather business go to a friend, not an enemy. My theory is it is not competition. Problems are always happening in production. I always tell the manufacturer that "it's not my problem, it's not his," I call to always solve the problem, not to get out of fixing the problem. We are all in the same boat (Uzzi, 1997: 51).

Unlike market relationships, which "go only by the letter," a production manager explained that among embedded ties, "I may come down to their factory on Saturday or Sunday if there is a problem" in order to work "things out to both our satisfaction" (Uzzi, 1997: 43). In these examples, a shared concern for partners' wellbeing drives efforts to prevent losses in the event of unforeseeable contingencies, thereby enabling participants to cope with vulnerability.

As another CEO explains, "Constant communication is the difference. It's just something you know. It's like having a friend. The small details really help in a crunch. They know we're thinking about them. And I feel free to ask, 'How are things going on your end, when will you have work for us?'” (Uzzi, 1997: 45). Here, the interviewee explains how the close relationship with embedded ties allowed for the sharing of proprietary information, which enabled firms to find work during slow 
periods. Again, the mutual concern manifested in these relationships allowed for participants to cope with vulnerability, in this case the potential for unemployment, lower wages, or bankruptcy, which in turn allowed employees to earn a wage sufficient to participate in the practices and activities constitutive of the common good of their community (Garcia-Ruiz \& Rodriguez-Lluesma, 2015).

In these examples, the relationships between embedded ties and their attitudes toward work follow a similar pattern to that discussed above (section one) regarding the nature of goods within networks of giving and receiving. Mutual commitment to the wellbeing of embedded ties shapes partners' attitudes toward other types of goods, especially external goods. Partners recognize their vulnerability and mutual dependence, and they act with a genuine concern for the wellbeing of embedded ties. Thus, these relationships manifest the central characteristics of networks of giving and receiving. As one interviewee explains, "Not everything in business works by the economic model" (Uzzi, 1997: 56).

\section{Cooperation and Just Generosity}

While Uzzi (1997) does not directly address the role of the virtues in this context, he maintains that the behavior characteristic of embedded ties manifests a genuinely disinterested and mutual concern. Uzzi (1997: 56) argues that "the motivation to cooperate when it is not in an individual's self-interest occurs because the expectations of embedded ties lag changes in economic incentives or persist against them, an outcome that is itself sustained by psychological processes that are set in motion by embedded ties." The perspective outlined in DRA suggests that this motivation to cooperate manifests the virtue of just generosity. By exercising a mutual non-calculative commitment to the wellbeing of close ties, participants are able to cope with vulnerability in a way that would not have been possible in the absence of such a commitment. As Uzzi (1997: 56) further explains:

What distinguishes this rationality from formal economic rationality is ... the fact that self-interest gives way to altruism: Actors strategically cooperate and equitably distribute both positive and negative outcomes. Thus, contrary to Adam Smith's quip that individuals do best for others by doing selfishly for themselves, the above evidence suggests that firms that act in the interest of others (and against their short-term interests) may do more for the collective economy and society than if they had followed purely selfish pursuits.

As such, the relationships between embedded ties manifest a similar structure to those shaped by the virtues of acknowledged dependence, wherein a non-calculative commitment to the wellbeing of fellow participants contributes to, and is recognized to contribute to, the individual's wellbeing (MacIntyre, 1999a: 158).

Although Uzzi (1997: 56, 61) uses the notion of "altruism" in the passage above, he further explains that within "networks of close ties, motivation is neither purely selfish or cooperative but an emergent property of the social structure within which actors are embedded." Similarly, MacIntyre (1999a: 160) notes, "It is of great importance not to confuse character ... informed by the virtue of just generosity, with altruism," which presupposes "a conception of human beings as divided in their inclinations and passions, some of those being self-regarding, others 
being other-regarding." Instead, MacIntyre (1999a: 102) argues that the virtues of acknowledged dependence allow participants to create and sustain networks of giving and receiving that are partially constitutive of the participants' common good, thus transcending the distinction between egoism and altruism. This suggests that the "social structure" characteristic of embedded ties is that of a network of giving and receiving.

This account also illustrates the distinct obligations characteristic of relationships of giving and receiving. As Uzzi (1997) argues, participants began to see themselves as engaged in a common project. But unlike the situation described by Hall (2011), wherein senior practitioners assisted junior participants, thereby enabling them to achieve the goods internal to the practice, the context of this example evidences mutual obligations between members in relationships of giving and receiving. Here, the primary concern is not the internal goods of the activity, since many participants had little knowledge of the ends of the production process (Beadle \& Knight, 2012), but rather the wellbeing of participants expressed through actions that enabled them to cope with vulnerability related to unforeseen contingencies. As such, vulnerability, as well as the need to preserve the relationships of giving and receiving through which participants were able to cope with such vulnerability, resulted in obligations to assist fellow participants in a manner distinct from the obligations founded upon the internal goods of practices. In this context, participants were obligated to treat each other benevolently, in accord with the virtue of just generosity (MacIntyre 1999a: 102).

\section{Action Explanations Between Embedded Ties}

Similarly, the role of the virtues is evident when contrasting alternative explanations for the actions of network partners, that is, embedded ties. Game theory predicts that cooperative players in a repeated game will defect when the end of the game is evident. Contrary to this prediction, Uzzi (1997: 55) found that "embedded firms continue to cooperate even after the end of the game is apparent." He describes a representative case where a manufacturer moved production to Asia and, as a result, had strong incentives to conceal this from network partners. Notifying network partners put the firm at a significant risk of receiving lower quality goods prior to relocating. As Uzzi (1997: 55) explains:

Yet the CEO of this manufacturer personally notified his embedded ties, because his relationships with them obliged him to help them adapt to the closing of his business, and his trust in them led him to believe that they would not shirk on quality. Consistent with his account, one of his contractors said that the jobber's personal visit to his shop reaffirmed their relationship, which he repaid with quality goods. The same manufacturer, however, did not inform those contractors with which it had arm's-length ties.

This example follows the same pattern-mutual concern for wellbeing driving a cooperative attitude toward external goods-as is typical of networks of giving and receiving, enabling participants to better cope with vulnerability.

Just generosity is also evident in the attitudes of trust between participants, which MacIntyre (2010) links closely with dispositions directed toward the needs of others. 
Relationships between embedded ties were characterized by "trust," involving an "absence of monitoring devices" and a lack of "calculativeness" (Uzzi, 1997: 43). Uzzi (1997: 45) explains the characteristics of trust between embedded ties as "a governance structure that resides in the social relationship between and among individuals and cognitively is based on heuristic rather than calculative processing." Further, Uzzi (1997: 43) explicitly notes the contrast between the modes of trust characteristic of embedded ties in his study and Williamson's (1993) claim that trust within commercial contexts is always calculative. In contrast, trust between embedded ties manifests a commitment to the needs of others that is characteristic of the virtues of acknowledged dependence, not the calculative behavior characteristic of rational choice or game theory (MacIntyre, 1999a: 159; 2016: 187-188). Thus, a mutual commitment to the wellbeing of fellow participants enabled embedded ties to cope with vulnerability through the establishment of non-calculative relationships that were based upon trust. These relationships manifest the central characteristics of the virtue of just generosity, and they cannot be explained by economic game theory.

One limitation of this example concerns the relationships between networks of giving and receiving and institutions. There exist similar reasons to expect conflict between virtuous participation in relationships of giving and receiving and the demands of institutions - whether viewed as organizations or in terms of institutional logics (Moore \& Grandy, 2017) — as the reasons to expect conflict between practices and institutions (MacIntyre, 1999a: 102, 2007: 194). It is possible to imagine conflict between the cooperative relationships characteristic of embedded ties and managers or regulators, who, having been shaped by a market logic (Almandoz, 2014) or the "norm of self-interest" (Grant \& Patil, 2012: 547; Miller, 1999; Ratner \& Miller, 2001), demand that organization members act more competitively. Thus, this example only partially illustrates the application of the framework drawn from $D R A$. Similarly, this example offers a context wherein "markets reward" the virtues (Beadle, 2008: 239), although further research is needed to understand the relationships between the practice of the virtues within networks of giving and receiving and organizational performance (see also Lawrence \& Maitlis, 2012).

\section{DISCUSSION AND CONCLUSION}

In this article, I have outlined the main themes of the framework introduced in $D R A$, arguing that this account extends previous research in the field of business ethics employing the virtues-goods-practices-institutions schema (Moore \& Beadle, 2006). The example outlined above (Uzzi, 1997) extends the empirical application of MacIntyre's theory of the virtues and illustrates the presence of networks of giving and receiving in an organizational and interorganizational context. In this section, I briefly outline several potential applications of the $D R A$ framework within business ethics that may offer important avenues for future research.

First, additional research in the field of business ethics is needed to distinguish the role of the virtues within practices from their role within networks of giving and receiving. One important question here concerns the relationships between fellow practitioners within the same organization and practitioners in different organizations. 
By comparing the role of the virtues within relationships between practitioners in the same organizations and their role in relationships between practitioners in different organizations, researchers may be able to disentangle the differing ways in which practices and networks of giving and receiving, respectively, promote the virtues within and between organizations. Similarly, researchers may gain a better understanding of the relationships between practices and networks of giving and receiving by comparing the formation of relationships of giving and receiving within practice-bearing institutions (Coe \& Beadle, 2008) and in organizational contexts wherein practices are marginalized (Bernacchio \& Couch, 2015: S132; MacIntyre, 1979; Sinnicks, 2014).

Thus, researchers may look for "extreme exemplars" (Eisenhardt \& Graeber, 2007: 27) where practices are effectively marginalized and look for the way in which networks of giving and receiving form in such contexts. Moore (2017: 146) raises this possibility when he notes that "some activities may have been practices in the past, or could have the potential to be practices in the future, but institutional corruption and acquisitiveness is such that there is barely any evidence of practice-like features." In such contexts researchers may examine the potential for networks of giving and receiving to sustain, to some degree, the practice of the virtues in such adverse conditions. Similarly, researchers may examine the role of virtuous relations of giving and receiving in reforming such activities so that they come to exhibit "practice-like features" (Moore, 2017: 146).

Another potential application of the framework outlined in this article concerns the link between practice-bearing institutions (Coe \& Beadle, 2008) and the common good of the wider community (Moore, 2012b). In $A V$, MacIntyre (2007: 203) warns of the danger that "a certain subversive arbitrariness will invade the moral life" unless a good that transcends the internal goods of practices is recognized. This concern has been repeatedly acknowledged (Beabout, 2012; Beadle, 2008; Beadle \& Moore, 2006; Fernando \& Moore, 2014; Moore, 2005a, 2012a, 2012b; Moore \& Beadle, 2006; Moore \& Grandy, 2017; Sinnicks, 2014; von Krogh et al., 2012), although, arguably, further research is needed to explain the contribution of practice-bearing institutions to the common good of wider communities. Consideration of the link between practice-bearing institutions and the common good has typically focused upon the notion of goodness of purpose (Moore, 2012a: 304, 2012b). Hence, existing research has followed MacIntyre's (2007: 189) claim that excellent products and performances figure centrally among the internal goods of practices. But MacIntyre (2007: 190) also identified the perfection of practitioners, "the good of a certain kind of life," as the second type of internal good characteristic of practices.

Thus, it is evident that organizations contribute to the common good in a variety of ways that include but also go beyond excellent goods and services, including providing employment and adequate wages so that employees and their families can participate in the range of practices and institutions found within their communities (Garcia-Ruiz \& Rodriguez-Lluesma, 2015; MacIntyre, 2011). The framework outlined above allows researchers to conceptualize organizations and organization members as participants in a range of networks of giving and receiving (MacIntyre, 1999a: 122) that extend beyond the confines of a single organization. Future research 
may explore the way in which the second type of internal good identified in $A V$, the perfection of practitioners, contributes to the formation of networks of giving and receiving extending beyond a particular organizational context.

Members of organizations are typically linked to various family members, friends, and neighbors who are dependent upon them for the resources and skills gained through employment. As the example above (Uzzi, 1997) illustrates, organizations and organization members are linked to members of other organizations who are dependent upon their willingness to engage in uncalculating actions (MacIntyre, 1999a: 126; Uzzi, 1997: 43) in order to cope with various forms of vulnerability. Similarly, organizations and organization members are linked to other stakeholders within the community through relations of giving and receiving of various types (Wicks et al., 1994). Thus, researchers employing the concepts outlined above may be able to link existing research in the field of MacIntyrean business ethics (Beadle, 2015) that focuses on practices with research concerning organizations and the common good (Sison \& Fontrodona, 2012, 2013), as well as with feminist, or care, approaches to stakeholder theory (see especially Burton \& Dunn, 1996; Wicks et al., 1994) that highlight the mutual dependence that exists between stakeholders (see also Argandona, 2011).

Drawing explicitly on care ethics, Maitlis and Lawrence (2012: 642) investigate "the discursive practices of [organization] members in concrete, ongoing, emotionally significant relationships." While Maitlis and Lawrence focus on team members within organizations, the account developed in DRA suggests that relationships of giving and receiving facilitate discursive reasoning directed toward the common good of community members, more generally (MacIntyre, 1999a: 135-141). Future research may focus on the specific role of networks of giving and receiving within and between organizations in facilitating discursive reasoning that contributes to the common good of stakeholders within and between organizations and in the larger community (see also Wicks et al., 1994).

\section{Implications for Managers}

The account of networks of giving and receiving and the virtues of acknowledged dependence developed in this article has important implications for the way in which managers understand themselves and their fellow employees as engaging in forms of moral agency. MacIntyre (1979, 1999b, 2007) has argued that organizations often present threats to moral agency because of their tendency to compartmentalize agents, confining their reasons for action within particular roles that abstract from broader ethical and political considerations. The account of organizations as practice-institution combinations (Moore, 2017: 11) first outlined in $A V$ and developed within business ethics research (Beadle, 2015) provides important resources for overcoming compartmentalization and explaining the nature of moral agency within an organizational context.

Much existing literature employing a MacIntyrean perspective within business ethics (Beadle, 2015: 5) has focused upon the role of management in facilitating the "proper ordering of internal and external goods," but insofar as the account of networks of giving and receiving developed in this article represents an extension of 
the practices-institutions framework, it suggests that managers face an added level of complexity in their attempts to understand themselves and their fellow organization members as moral agents. Accordingly, managers must acknowledge both the need to promote and preserve their core practice (Beadle \& Moore, 2006) and their dependence upon various networks of giving and receiving (MacIntyre, 1999a). Similarly, managers must recognize that fellow organizations members' identities are shaped both by their "craft" (MacIntyre, 1990, 2007; Moore, 2005b) and by their participation in various networks of giving and receiving (MacIntyre, 1999a).

This involves the further recognition that, at least in some cases, the pursuit of external goods at the expense of internal goods may be the result not of the vice of acquisitiveness (MacIntyre, 2007: 194), but of need, the needs of fellow organization members and those to whom they are related within networks of giving and receiving. Thus, managers attempting to engage in genuine moral agency within organizations (MacIntyre, 1979) must understand the implications of their actions both upon the core practice of their organizations and upon the range of networks of giving and receiving in which organization members participate.

In the face of urgent need, moral agency may require managers to make very difficult decisions, for instance, decisions that, to some degree, set aside the fundamental aims of the organizations (MacIntyre, 2010: 8), including, at least to some degree, the preservation of the core practice (Moore, 2005a). This may involve corporate downsizing (Orlando, 1999) or the automation of some portion of the production process (see Breen, 2007) in order to avoid bankruptcy or maintain competiveness, thus preserving some aspects of the practice, while marginalizing others, (Moore, 2017) and continuing to employ part of the workforce. Faced with these situations, managers must make greater efforts to communicate the goods at stake, typically goods associated with the needs of various stakeholders, both employees and those who reply upon them for the resources needed to participate in various practices (Garcia-Ruiz \& Rodriguez-Lluesma, 2015; MacIntyre, 2011). Practical reasoning in such contexts will involve more than balancing internal and external goods (Beadle, 2013), extending to a consideration of the particular needs of stakeholders, especially stakeholders' urgent needs (MacIntyre, 1999a: 122).

Managers need the virtue of practice wisdom (Beabout, 2012; MacIntyre, 1999a) and moral imagination (Werhane, 1998) as they seek to meet the needs of fellow participants in relationships of giving and receiving while preserving the integrity of their core practice. In these situations, solutions will often be less than ideal but will be the best that is possible given the circumstances (Hartman, 1996: 85). Likewise, in addition to virtues such as justice, courage, and truthfulness (MacIntyre, 2007: 192), virtues needed to sustain the core practice, managers must recognize the importance of the virtues of acknowledged dependence (MacIntyre, 1999a), virtues such as just generosity, misericordia, and beneficence, insofar as organization members participate in various networks of giving and receiving that are vital to their flourishing. Since these virtues typically require a willingness to treat the needs of others as reasons for action, managers must also recognize that well-ordered relationships with stakeholders will often require more than what is demanded by a strict consideration of commutative justice. As noted above, managers must make 
greater efforts to communicate the requirements of these additional virtues in specific situations to fellow organization members, enabling organization members to appreciate both the importance of the internal goods of the their practice and the way in which the common good of the community is constituted by relationships of uncalculated giving and receiving.

\section{Conclusion}

In this article, I have followed Macintyre's (1999a: ix) claim that DRA represents an extension of his earlier account of the virtues (2007) by arguing that the notion of networks of giving and receiving and the corresponding virtues of acknowledged dependence-including just generosity, misericordia, and beneficence-extend previous research in the field of business ethics (Beadle, 2015) employing the virtues-goods-practices-institutions schema (Moore \& Beadle, 2006). The framework drawn from $D R A$ highlights goods and virtues that have not been adequately emphasized, allowing researchers to extend previous research concerning practices (Beadle, 2015) in order to gain a more adequate grasp of the role of the virtues in an organizational and interorganizational context. In order to illustrate the potential for future research, I have developed an example drawn from social network theory (Uzzi, 1997) that demonstrates the way in which a mutual commitment to wellbeing between members of a number of organizations facilitates relationships of giving and receiving that enable participants to cope with vulnerability. This example suggests an important avenue for future research in business ethics that can better conceptualize the relationship between the role of the virtues within practices and their role in networks of giving and receiving found within and between organizations.

\section{ACKNOWLEDGEMENTS}

I would like to thank Denis Arnold and two anonymous reviewers for insightful comments and generous assistance in the preparation of this article. I also thank Ed Hartman, Ron Beadle, Angus Robson, Kelvin Knight, Robert Couch, Jeff Nicholas, Carlos Rodríguez-Lluesma, Marco D'Avenia, and Philip DeMahy for comments and criticism on earlier drafts, as well as the participants at the 10th Annual ISME Conference in Wroclaw, Poland where a version of this article was first presented.

\section{NOTES}

1. MacIntyre (1999a: 122-123) states, "I have already remarked that the practices of receiving and giving informed by particular just generosity are primarily exercised by other members of our own community related to us by their and our roles. Yet this may have been misleading in more than one way. First of all we are often members of more than one community and we may find a place within more than one network of giving and receiving. Moreover, we move in and out of communities. If therefore I continue to speak of the community or network to which someone belongs, the reader should supply the missing arm of the disjunction: 'community or communities,' 'network or networks."'

2. "The good that is our final end does not compete with other goods. We value other goods both for their own sake and for what they contribute to our lives as a whole, as a unity. The good that is our final end constitutes our lives as wholes, as unities. So in acting for the sake of achieving some particular good, we also act for the sake of achieving our final end, and it is this that, if we act rightly, gives our lives a directedness toward that end" (MacIntyre, 2016: 229). 
3. In $D R A$, MacIntyre focuses on a complementary mode of overlap wherein networks of giving and receiving facilitate engagement in the practice of politics (see chapters 9 and 10).

4. MacIntyre (1999a: ix) introduces DRA as "a correction of some of my earlier enquiries," including $A V$. He further notes (1999a: x; italics added), "I now judge that I was in error in supposing an ethics independent of biology to be possible .... One such failure, of immense importance on its own account, is the nature and extent of human vulnerability and disability. And by not reckoning adequately with this central feature of human life I had necessarily failed to notice some other important aspects of the part that the virtues play in human life."

5. MacIntyre notes (1999a: 68), "The threefold classification of ascriptions of good which I have elaborated is incomplete. We also and at a primary stage recognize as good and call good the pleasures attained in the satisfaction of felt bodily wants, indeed of felt wants more generally."

6. Aquinas (ST II-II Q. 23 art. 1) is even more explicit, stating, "According to the Philosopher (Ethic. viii, 2, 3) not every love has the character of friendship, but that love which is together with benevolence, when, to wit, we love someone so as to wish good to him."

7. "Now those who wish goods to their friend for the friend's own sake are friends most of all; for they have this attitude because of the friend himself, not coincidentally. Hence these people's friendship lasts as long as they are good; and virtue is enduring" (Aristotle: NE 1156b: 5-10).

8. As MacIntyre (1999a: 113) states, "If one is to find one's place within a network of givers and receivers...the achievement of one's individual good is to be understood as inseparable from the achievement of the common good."

\section{REFERENCES}

Almandoz, J. 2014. Founding teams as carriers of competing logics. Administrative Science Quarterly, 59(3): 442-472.

Aquinas, T. 1981. Summa theologiae. New York: Christian Classics.

Argandona, A. 2011. Beyond contracts: Love in firms. Journal of Business Ethics, 99(1): $77-85$.

Aristotle. 1999. Nicomachean ethics. Indianapolis, IN: Hackett Publishing Company.

Armstrong, A. E. 2006. Toward a strong virtue ethics for nursing practice. Nursing Philosopy, 7(3): 110-124.

2007. Nursing ethics: A virtue based approach. London: Palgrave Macmillan.

Beabout, G. 2012. Management as a domain-relative practice that requires and develops practical wisdom. Business Ethics Quarterly, 22(2): 405-432.

Beadle, R. 2008. Why business cannot be a practice. Analyse \& Kritik, 30: 229-241.

. 2013. Managerial work in a practice embodying institution. Journal of Business Ethics, 113(4): 679-690.

2015. MacIntyre's influence on business ethics. In A. Sison, G. Beabout, \&

I. Ferrero (Eds.), Handbook of virtue ethics in business and management: 1-9. New York: Springer.

Beadle, R., \& Moore, G. 2006. MacIntyre on virtue and organization. Organization Studies, 27(3): 323-340.

Beadle, R., \& Knight, K. 2012. Virtue and meaningful work. Business Ethics Quarterly, 22(2): 433-450.

Bernacchio, C., \& Couch, R. 2015. The virtue of participatory governance. Business Ethics: A European Review, 24(S2): S130-S143.

Breen, K. 2007. Work and emancipatory practice: A recovery of human beings' productive capacities. Res Publica, 13(4): 381-414.

Burton, B., \& Dunn, C. 1996. Feminist ethics as moral grounding for stakeholder theory. Business Ethics Quarterly, 6(2): 133-147.

Coe, S., \& Beadle, R. 2008. Could we know a practice-embodying institution if we saw one?

Philosophy of Management, 7(1): 9-19. 
Dunne, J. 2002. Ethics revised: Flourising as vunerable and dependent. A critical notice of Alasdair MacIntyre's dependent rational animals. International Journal of Philosopical Studies, 10(3): 339-363.

Eisenhardt, K., \& Graebner, M. 2007. Theory building from cases: opportunities and challenges. Academy of Management Review, 50(1): 25-32.

Fernandon, M., \& Moore, G. 2014. MacIntyrean virtue ethics in business: A cross-cultural comparison. Journal of Business Ethics, 132(1): 185-202.

Ferrero, I., \& Sison, A. J. G. 2014. A quantitative analysis of authors, schools and themes in virtue ethics articles in business ethics and management journals (1980-2011).

Business Ethics European Review, 23: 375-400.

Fontrodona, J., \& Sison, A. J. G. 2006. The nature of the firm, agency theory and shareholder theory: A critique from philosophical anthropology. Journal of Business Ethics, 66(1): 33-42.

Garcia-Ruiz, P., \& Rodriguez-Lluesma, C. 2015. Consumption practices: A virtue ethics approach. Business Ethics Quarterly, 24(4): 509-531.

Grant, A. M. 2007. Relational job design and the motivation to make a prosocial difference. Academy of Management Review, 32(2): 393-417.

. 2008. Does intrinsic motivation fuel the prosocial fire? Motivational synergy in predicting persistence, performance, and productivity. Journal of Applied Psychology, 93(1): 48-58.

2014. Give and take: Why helping others drives our success. London: Penguin Books.

Grant, A. M., Dutton, J. E., \& Rosso, B. D. 2008. Giving commitment: Employee support programs and the prosocial sensemaking process. Academy of Management Journal, 51(5): 898-918.

Grant, A. M., \& Gino, F. 2010. A little thanks goes a long way: Explaining why gratitude expressions motivate prosocial behavior. Journal of Personality and Social Psychology, 98(6): 946-55.

Grant, A. M., \& Patil, S. 2012. Challenging the norm of self-interest: Minority influence and transitions to helping norms in work units. Academy of Management Review, 37(4): 547-568.

Grant, A. M., \& Mayer, D. 2009. Good soldiers and good actors: Prosocial and impression management motives as interactive predictors of affiliative citzenship behaviors. Journal of Applied Psychology, 94(4): 900-912.

Hall, D. E. 2011. The guild of surgeons as a tradition of moral enquiry. Medicine and Philosophy, 36(2): 114-132.

Hartman, E. 1996. Organizational ethics and the good life. Oxford: Oxford University Press.

2013. Virtues in business: Conversations with Aristotle. Cambridge: Cambridge University Press.

Jensen, M., \& Meckling, W. 1976. Theory of the firm: Managerial behavior, agency costs and ownership structure. Journal of Financial Economics, (3)4: 305-360.

Lawrence, T., \& Maitlis, S. 2012. Care and possibility: Enacting an ethic of care through narrative care. Academy of Management Review, 37(4): 641-663.

MacIntyre, A. 1979. Corporate modernity and moral judgement: Are they mutually exclusive. In K. Goodpaster \& K. Sayre (Eds.), Ethics and problems of the 21st century: 122-138. Notre Dame: University of Notre Dame Press.

. 1989. Whose justice? Which rationality? Notre Dame: University of Notre

Dame Press. 
1990. Three rival versions of moral enquiry: Encyclopaedia, genealogy, and tradition. Notre Dame: University of Notre Dame Press.

1994. A partial response to my critics. In J. Horton \& S. Mendus (Eds.), After MacIntyre: 283-304. Notre Dame: University of Notre Dame Press.

. 1998. Politics, philosophy, and the common good. In L. Knight (Ed.), The MacIntyre reader: 235-253. Notre Dame: University of Notre Dame Press.

. 1999a. Dependent rational animals: Why human beings need the virtues. Chicago \& LaSalle: Open Court Publising.

1999b. Social structures and their threats to moral agency. Philosophy, 74(3): 311-329. . 2000. The need for a standard of care. In L. P. Francis \& A. Silvers (Eds.), Americans with disabilities: Exploring implications of the law for individuals and institutions: 81-86. Abingdon, UK: Routledge.

. 2007. After virtue: A study in moral theory (3rd ed.). Notre Dame: University of

Notre Dame Press.

2008. What more needs to be said? A beginning, although only a beginning, at saying it. Analyse and Kritik, 30: 261-281.

-2010. Danish ethical demands and French common goods: Two moral philosophies.

European Journal of Philosophy, 18(1): 1-16.

. 2011. Where we were, where we are, where we need to be. In P. Blackledge \&

K. Knight (Eds.), Virtue and politics: 307-334. Notre Dame: University of Notre Dame Press.

. 2016. Ethics in the conflicts of modernity: An essay on desire, practical reasoning, and narrative. Cambridge: Cambridge University Press.

MacIntrye, A., \& Voorhoeve, A. 2011. The illusion of self-sufficiency. In A. Voorhoeve (Ed.), Conversations on ethics: 111-132. Oxford: Oxford University Press.

Melé, D. 2009. The practice of networking: An ethical approach. Journal of Business Ethics, 90(4): 487-503.

. 2012. The firm as a "community of persons": A pillar of humanistic business ethos. Journal of Business Ethics, 106(1): 89-101.

Miller, D. 1999. The norm of self-interest. American Psychologist, 54(12): 1053-1060.

Moore, G. 2005a. Corporate character: Modern virtue ethics and the virtuous corporation.

Business Ethics Quarterly, 15(4): 659-685.

. 2005b. Humanizing business: A modern virtues ethics approach. Business Ethics

Quarterly, 15(2): 237-255.

. 2008. Review: Dependent rational animals: Why human beings need the virtues.

Philosophy of Management, 7(1): 123-129.

.2012a. The virtue of governance, the governance of virtue. Business Ethics Quarterly, 22(2): 293-318.

. 2012b. Virtue in business: Alliance Boots and an empirical exploration of MacIntyre's conceptual framework. Organization Studies, 33(3): 363-387.

. 2017. Virtue at work: Ethics for individuals, managers, and organizations.

Cambridge: Cambridge University Press.

Moore, G., \& Beadle, R. 2006. In search of organizational virtue in business: Agents, goods, practices, and environments. Organization Studies, 27(3): 369-389.

Moore, G., \& Grandy, G. 2017. Bringing morality back in: Institutional theory and MacIntyre. Journal of Management Inquiry, 26(2) 1-19.

Orlando, J. 1999. The fourth wave: The ethics of corporate downsizing. Business Ethics

Quarterly, 9(2): 295-314. 
Philpott, D. 2012. Just and unjust peace: An ethic of political reconciliation. Oxford: Oxford University Press.

Ratner, R., \& Miller, D. 2001. The norm of self-interest and its effects on social action. Journal of Personality and Social Psychology, 81(1): 5-16.

Rhonheimer, M. 2011. The perspective of morality: Philosophical foundations of Thomistic virtue ethics. Washington, DC: Georgetown University Press.

Sellman, D. 2000. Alasdair MacIntyre and the professional practice of nursing. Nursing Philosophy, 1(1): 26-33.

. 2011. What makes a good nurse: Why the virtues are important for nursing. London: Jessica Kingsley Publishing.

Setiya, K. 2007. Reasons without rationalism. Princeton, NJ: Princeton University Press.

Sinnicks, M. 2014. Practices, governance, and politics: Applying MacIntyre's ethics to business. Business Ethics Quarterly, 24(2): 229-249.

Sison, A. J., \& Fontrodona, J. 2012. The common good of the firm in the AristotelianThomistic tradition. Business Ethics Quarterly, 22(2): 211-246.

. 2013. Participating in the common good of the firm. Journal of Business Ethics, 113(4): 611-625.

Uzzi, B. 1997. Social structure and competition in interfirm networks: The paradox of embeddedness. Administrative Science Quarterly, 42(1): 35-67.

von Krogh, G., Haefliger, S., Spaeth, S., \& Wallin, M. W. 2012. Carrots and rainbows: Motivation and social practice in open source software development. MIS Quarterly, 36(2): 649-676.

Werhane, P. 1998. Moral imagination and the search for ethical decision-making in management. Business Ethics Quarterly, special issue: 75-98.

Wicks, A., Gilbert, D., \& Freeman, R. 1994. A feminist reinterpretation of the stakeholder concept. Business Ethics Quarterly, 4(4): 475-497.

Williamson, O. 1993. Calculativeness, trust, and economic organization. Journal of Law \& Economics, 36(1.2): 453-486.

Wolfe, C. J 2017. Alasdair MacIntyre on the grand end conception of practical reasoning. Polis: The Journal for Ancient Greek Political Thought, 33(2): 312-330. 